Research Paper

\title{
Senescence Process in Primary Wilms' Tumor Cell Culture Induced by p53 Independent p21 Expression
}

\author{
Korkiat Theerakitthanakul ${ }^{1}$, Jirakrit Saetang ${ }^{1}$, Jirasak Kruatong ${ }^{1}$, Potchanapond Graidist ${ }^{1}$, Pritsana \\ Raungrut ${ }^{1}$, Kanita Kayasut ${ }^{2}$, Surasak Sangkhathat ${ }^{3 \otimes}$ \\ 1. Department of Biomedical Sciences, Faculty of Medicine, Prince of Songkla University, Hat Yai, Songkhla, Thailand 90110; \\ 2. Department of Pathology, Faculty of Medicine, Prince of Songkla University, Hat Yai, Songkhla, Thailand 90110; \\ 3. Department of Surgery, Faculty of Medicine, Prince of Songkla University, Hat Yai, Songkhla, Thailand 90110. \\ $\triangle$ Corresponding author: Surasak Sangkhathat, MD.,Ph.D. Department of Surgery, Faculty of Medicine, Prince of Songkla University, Hat Yai, Songkhla, \\ Thailand 90110, surasak.sa@psu.ac.th.
}

(1) Ivyspring International Publisher. Reproduction is permitted for personal, noncommercial use, provided that the article is in whole, unmodified, and properly cited. See http://ivyspring.com/terms for terms and conditions.

Received: 2016.05.29; Accepted: 2016.07.09; Published: 2016.09.02

\begin{abstract}
Wilms tumor (WT) is an embryonal tumor occurring in developing kidney tissue. WT cells showing invasive cancer characteristics, also retain renal stem cell behaviours. In-vitro culture of WT is hampered by limited replicative potential. This study aimed to establish a longterm culture of WT cells to enable the study of molecular events to attempt to explain its cellular senescence. Methods: Primary cell cultures from fresh WT tumor specimen were established. Of 5 cultures tried, only 1 could be propagated for more than 7 passages. One culture, identified as PSU-SK-1, could be maintained $>35$ passages and was then subjected to molecular characterization and evaluation for cancer characteristics. The cells consistently harbored concomitant mutations of CTNNBI (Ser45Pro) and WTI (Arg413Stop) thorough the cultivation. On Transwell invasion assays, the cells exhibited migration and invasion at $55 \%$ and $27 \%$ capability of the lung cancer cells, A549. On gelatin zymography, PSU-SK-1 showed high expression of the matrix metaloproteinase. The cells exhibited continuous proliferation with 24-hour doubling time until passages 28-30 when the growth slowed, showing increased cell size, retention of cells in $\mathrm{Gl} / \mathrm{S}$ proportion and positive $\beta$-galactosidase staining. As with those evidence of senescence in advanced cell passages, expression of $\mathrm{p} 21$ and cyclin D1 increased when the expression of $\beta$-catenin and its downstream protein, TCF, declined. There was also loss-of-expression of p53 in this cell line. In conclusion, cellular senescence was responsible for limited proliferation in the primary culture of WT, which was also associated with increased expression of p21 and was independent of p53 expression. Decreased activation of the Wnt signalling might explain the induction of p21 expression.
\end{abstract}

Key words: Wilms tumor, Primary cell culture, Senescence.

\section{Introduction}

Wilms' tumor (nephroblastoma or WT) is the most common renal tumor in the pediatric age group [1]. The tumor occurs in children aged less than 5 years without any specific risk factors [2]. Although details of the pathogenesis of WT are not clear at this time, the tumor arises in a histologically malformed kidney with nephrogenic rest [3]. Ten percent portion of WTs are associated with certain congenital syndromes such as WAGR (WTT, Aniridia, Genitourinary anomaly, Mental $\underline{\text { Retardation) }}$ association, Denys Drash syndrome and Beckwith Wiedermann syndrome [4]. Such familial cases are associated with recurrent cytogenetic lesions at chromosome 11q13 and corresponding germline mutations involving the WT1 gene [5]. Recent evidences have added 2 more candidates, CTNNB1 and WTX as genetic drivers of the tumor [6,7]. Unlike WT1, mutations of CTNNB1 and WTX occur at the tissue level and when co-occurrence of WT1 and CTNNB1 mutations are common, lesions on WTX 
seems to be mutually exclusive from them [8]. Functional interaction among the 3 genes in WT pathogenesis is an issue being focus by researchers in this area [2].

Mutations of WT1 are responsible for abnormalities in metanephric mesenchymal differentiation and the resulting nephrogenic rest is a predisposing condition for tumorigenesis promoted by CTNNB1 mutations $[9,10]$. The histological characteristics of WT consist of blast cells with varying degrees of differentiation into the renal tubular epithelium and the stroma. An intact WT1 signal is required for the tumor subset promoted by WTX [10]. Our previous study showed that WT1 expression is essential for growth in primary culture of WT with wildtype WT1 [11].

Although primary cultures of WT have been reported in various studies, longterm culture and immortalization of the cells has only rarely been reported [12-16]. Most longterm cultures have had complex genetic abnormalities other than the common mutations described above and were not good models for the molecular study of WT [17]. In addition, some of the cell lines supposed to be derived from WT were later proven to originate from other cancers $[12,18]$. The main obstacles for establishment of longterm ex-vivo cultures of WT are the fact that differentiating WT cells need continuous growth promoting signals that require interaction with the extracellular microenvironment. In addition, because the majority of WTs have no molecular signature and retain the potential to differentiate to various forms, it might be difficult to discriminate the actual WT tumor cells from other clonal origins such as benign epithelial cells and fibroblasts [16].

In this study, we established primary cultures from WT cells with known WT1 mutations and evaluated their growth characteristics. Only one continuous culture could be established. The cells were evaluated for malignant characteristics of WT and studied for possible molecular mechanisms of growth retardation in the late passages.

\section{Methods}

The study was approved by the Human Research Ethical Committee of the Faculty of Medicine, Prince of Songkla University and the Animal Research Committee of Prince of Songkla University.

\section{Isolation and primary culture of WT}

To isolate WT cells, fresh tumor specimens were obtained from 5 cases of WT known to harbor WT1 mutations. The characteristics of the mutations detected in these cases were presented in our previous publication [11]. Snap tissue specimens were divided into 3 parts, for histopathological diagnosis, frozen for nucleic acid study and isolation of cancer cells. The fresh tumor tissues were sliced with a scalpel into $0.1-0.5 \mathrm{~cm}^{3}$ pieces and washed with Dulbecco's PBS-antibiotic mixture (Thermo Fisher Scientific, Inc.). The tissues were then incubated overnight with $2 \mathrm{U} / \mathrm{ml}$ dispase (Gibco, BRL, Inc.) at $4^{\circ} \mathrm{C}$ on a stirrer at 100 rounds per minute (rpm), followed by digestion with $160 \mu \mathrm{g} / \mathrm{ml}$ of collagenase A (Sigma, St Louise, $\mathrm{MO}, \mathrm{USA})$ at $37^{\circ} \mathrm{C}$ for 3 hours.

The digested cells were collected and cultured in Dulbecco's modified Eagle's medium (DMEM; Invitrogen, Carlsbad, CA, USA) supplemented with $10 \%$ fetal bovine serum (FBS; Invitrogen, Inc.) until the cells had grown in a confluent monolayer. In order to reduce contamination from fibroblasts, the first 3 culture passages were subjected to differential trypsinization, using $0.025 \%$ trypsin and short (15-second) incubation. A maintenance culture was done in a $25 \mathrm{ml}$ flask with DMEM supplemented with $10 \%$ FBS and 100 units $/ \mathrm{ml}$ of streptomycin and 100 $\mu \mathrm{g} / \mathrm{ml}$ penicillin. The culture medium was replaced every 2 days and nearly confluent cultures (usually $80 \%$ confluence) was propagated every 3 days. For cryopreservation, the cells were frozen in DMEM containing 10\% DMSO (Sigma Aldrich, St.Louise, $\mathrm{MO}$ ) and $90 \%$ FBS and stored in liquid nitrogen. Culturing of the control cell lines including HEK293 and A549 used our standard laboratory protocols.

\section{Cellular and molecular characterization of the PSU-SK-1}

Of the 5 primary cultures, only 1 could be maintained for more than 7 passages and this culture was PSU-SK-1. To characterize the cellular morphology and expression of WT-related protein markers, the cells from passage 10 were cultured in a chambered slide until $60 \%$ confluence. Then the adhered cells were washed with DPBS and fixed with $4 \%$ paraformaldehyde. Basic histological staining was done with Hematoxylin and Eosin (H\&E). The immunocytochemistry assay used primary antibodies against $\beta$-catenin 1:1,000 (6B3, BD Bioscience, Inc.), Cytokeratin 1:300 (M3515, AE1/AE3), MyoD1 1:100 and Myogenin 1:100 (Dako, Denmark). The prepared cells on slides were blocked with $10 \mathrm{mg} / \mathrm{L}$ bovine serum albumin (BSA), and incubated with each primary antibody for $60 \mathrm{~min}$. After that, a secondary antibody conjugated with horse radish peroxidase (HRP) was added and the incubation was allowed to proceed for $60 \mathrm{~min}$ at $37^{\circ} \mathrm{C}$. The immunohistochemistry of the corresponding tumor tissue was studied using the immunopathological procedure of our Department of Pathology (ISO 
15190).

Genetic studies of the cell line aimed to confirm the mutations detected in the index case and to look for cytogenetic abnormalities in the tumor cells. DNA from PSU-SK-1 passage 20 was used as a template. To study for mutations on WT1, CTNNB1, WTX and $p 53$, polymerase chain reactions (PCR) followed by direct sequencing were performed. The study covered exons 2-4 of CTNNB1, the whole coding sequence of WT1 and WTX and exons 5-8 of p53. Leukocyte DNA from the index case was also studied for mutations of WT1. The PCR primers and conditions can be provided on request. The cytogenetic study used G-band karyotyping. Interpretations of the karyotyping were based on the International System for Human Cytogenetic Nomenclature (1995). The modal chromosome number was determined from 20 cells.

\section{Growth and cell cycle study}

To characterize growth and doubling time of the PSU-SK-1 cell line, $2 \times 10^{4}$ cells were seeded in each well of a 96-well plate. The MTT (3-(4,5-dimethylthiazol-2-yl)-2,5-diphenyltetrazolium bromide, Gibco, BRL) method was used to detect cell viability as a function of cell growth and contact inhibition. Light absorbance at $570 \mathrm{~nm}$ was measured every 24 hours from day 1 to day 7 . The growth curves were drawn by plotting the means and standard deviations of three independent experiments. Doubling time was calculated from growth in the log phase.

Growth potential of the cells in different passages was studied by the 3T3 propagation method. In brief, PSU-SK-1 cells were cultured in a $25-\mathrm{ml}$ flask and propagated in a 1:3 ratio when the culture reached $80 \%$ confluence, every 3-5 days. Graphs were plotted between number of passages and days of culture.

\section{Study of cancer characteristics of PSU-SK-1}

In order to demonstrate that PSU-SK-1 was derived from cancer cells, in vitro cancer characteristics of the cells were studied. The tests included wound healing assays, migration and invasion studies, gelatin zymography and anchorage independent growth studies in soft agar culture and xenotransplantation in mice.

\section{Wound healing assay}

The study of horizontal growth and migration used a wound healing assay. $5 \times 10^{5}$ PSU-SK-1 cells were seeded in each well of a 6-well plate and cultured until confluence. A linear wound was created on the monolayer of each culture by a $100 \mu \mathrm{l}$ pipette tip (yellow tip). Closure of the wounds was observed under a phase contrast microscope every 6 hours until the healing was completed.

\section{Invasion and migration assays}

The test for invasion ability of PSU-SK-1 were performed by using a Transwell $8.0 \mu \mathrm{m}$ polycarbonate membrane chamber of $6.5 \mathrm{~mm}$ diameter in 24-well plate (Costar, Cambridge, MA, USA) coated with 0.3 $\mathrm{g} / \mathrm{L}$ of Matrigel (Collaborative Research Inc., Bedford, MA, USA). $10^{5}$ cells of PSU-SK-1 in culture medium containing FBS were added into the upper compartment of the chamber, and incubated at $37^{\circ} \mathrm{C}$ in a $\mathrm{CO}_{2}$ incubator for 6 hours. The filters were fixed with methanol and stained with $0.5 \%$ crystal violet in $25 \%$ methanol for 1 hour, before rinsing with tap water. The numbers of invaded cells in five random microscopic fields (10X) were counted and reported as number of cells per well. The results showed represented mean value and standard deviation of the number of invaded cells from three independent experiments, each carried out in triplicate. Motility assays were performed in a similar fashion to the invasion assay, except no Matrigel coating was applied to the upper surface of the Transwell filters. A lung cancer cell line with comparable cell size, A569, was used as a positive control.

\section{Gelatin zymography}

Gelatin zymography was used to evaluate the capability of the cells to produce matrix metalloproteinases (MMPs) as this is essential for interaction between cancer cells and the extracellular matrix. PSU-SK-1 cells were starved by culturing in the medium without FBS for 24 hours before collection of the condition medium. The condition medium was mixed with 5X SDS sample buffer before separation in a $120 \mathrm{~g} / \mathrm{L}$ SDS-PAGE containing 1 $\mathrm{mg} / \mathrm{mL}$ gelatin (Sigma, St. Louis, MO, USA). After electrophoresis at $200 \mathrm{~V}$ for 1 hour, the gel was washed in a $25 \mathrm{~mL} / \mathrm{L}$ of Triton X-100 (Amersham, Piscataway, NJ, USA) solution twice. The gel was then incubated in buffer containing $50 \mathrm{mmol} / \mathrm{L}$ Tris- $\mathrm{HCl}$ (Amersham, Piscataway, NJ, USA), pH 7.5, 10 $\mathrm{mmol} / \mathrm{L} \mathrm{CaCl}_{2}$ (Merck, Denmark), $1 \mathrm{mmol} / \mathrm{L} \mathrm{ZnCl}_{2}$ (Merck, Denmark), $10 \mathrm{~mL} / \mathrm{L}$ Triton X-100 for 16-18 hours, after which the gel was stained with $5 \mathrm{~g} / \mathrm{L}$ Coomassie blue in $300 \mathrm{~mL} / \mathrm{L}$ methanol and 100 $\mathrm{mL} /$ Lactic acid. After destaining, the clear band of gelatinolytic activity was documented for size determination using Bio-rad GS700 gel scanner (Bio-rad, Hercules, CA, USA). Conditioned media from A569 was used as a positive control and DMEM without FBS was used as a negative control.

\section{Anchorage independent growth in soft agar and tumorigenesis in nude mice}

To assess the anchorage independent growth of 
PSU-SK-1, colony formations in soft agar were initiated. Trypsinized cells were suspended in a top layer of DMEM containing 10\% FBS and $0.4 \%$ agarose at 5,000 cells per well in a 6-well plate with a bottom layer of DMEM containing 10\% FBS and 1\% agarose. After 4 weeks of culture, the cells were stained with $0.5 \mathrm{~mL}$ crystal violet for 1 hour and visualized for number of colonies under light microscope.

$\mathrm{BALB} / \mathrm{c}$, 5-week-old female nude mice were purchased from the National Laboratory Animal Center, Mahidol University (Bangkok, Thailand). 200-500 $\mu 1$ PSU-SK-1 cells suspended in DPBS at a density of $10^{7}$ cells $/ \mathrm{ml}$ were injected into the subcutaneous tissue of the nude mice. The experiments were performed in triplicate.

\section{Study of senescence and senescence associated $\beta$-galactosidase staining}

To study the growth dynamics of PSU-SK-1 in different passages, cell cycle studies were performed in cells from passages 5-30. Cells in the log phase of growth (second day of seeding) were trypsinized and fixed in cold $70 \%$ ethanol for at least 1 hour, then stored at $-20^{\circ} \mathrm{C}$. The thawed cells were washed with PBS, treated with RNAse $(1 \mathrm{mg} / \mathrm{ml})$ and stained with propidium iodide $(50 \mathrm{mg} / \mathrm{ml})$ for 30 minutes at $4^{\circ} \mathrm{C}$. DNA content analysis was performed on an EPICS ELITE flow cytometer (Beckman Coulter). The cell cycle distributions were analysed using ModFit LT2.0 software.

$\beta$-galactosidase staining was performed to evaluate the amount of cells entering the senescence process. Cells grown in 6-well plates were washed with PBS ( $\mathrm{pH} 7.2$ ), fixed for 10 minutes with $4 \%$ paraformaldehyde, and again washed with PBS $(\mathrm{pH}$ 7.2) plus $1 \mathrm{mM} \mathrm{MgCl}$. A volume of $1.2 \mathrm{ml}$ of staining solution containing $1 \mathrm{mg} / \mathrm{ml}$ X-Gal, $0.12 \mathrm{mM}$ $\mathrm{K}_{3} \mathrm{Fe}(\mathrm{CN})_{6}, 0.12 \mathrm{mM} \mathrm{K}{ }_{4} \mathrm{Fe}(\mathrm{CN})_{6}$, and $1 \mathrm{mM} \mathrm{MgCl}_{2}$ in PBS ( $\mathrm{pH}$ 6.0) was added. After 6 hours of incubation at $37^{\circ} \mathrm{C}$, the staining was stopped by washing with PBS plus $1 \mathrm{mM} \mathrm{MgCl} 2$ (pH 7.2). The results were visualized under a light microscope.

\section{Western blotting study}

To study the expression of candidate proteins in WT development (including WT1, WTX and $\beta$-catenin), proteins in the Wnt signaling pathway ( $\beta$-catenin, Axin1 and TCF) and proteins involved in cell cycle control (p21, p53 and cyclin D1), Western blotting studies were performed using total protein extracted from PSU-SK-1 from passages 5, 20 and 35. Total protein was extracted from the cultures by using RIPA lysis buffer and measured by Bradford's method (Bio-Rad, CA, USA). Equal amounts of protein lysates were subjected to $12 \%$ SDS-PAGE and transferred to a Polyvinylidene difluoride (PVDF) membrane (Bio-Rad), which were then blocked with $5 \%$ non-fat milk in TBST $(0.5 \%$ Tween $20,154 \mathrm{mM}$ $\mathrm{NaCl}, 40 \mathrm{mM}$ Tris- $\mathrm{HCl}, 48 \mathrm{mM}$ Tris-base) for 1 hour. After blocking, the membranes were incubated with primary antibodies (the list of primary antibodies can be provided on request). GAPDH (Calbiochem, Darmstadt, Germany) and a-Tubulin (Cell Signalling Technology, CA, USA) were used as loading controls. Bound antibodies were detected by donkey anti-rabbit or sheep anti-mouse HRP conjugated antibodies and visualized with chemiluminescence detection using SuperSignal West Dura substrate (Pierce, IL, USA).

\section{Results}

Of the 5 primary cultures from WT specimens, only 1 culture could be propagated beyond passage 7 . One culture had bacterial contamination and needed to be discarded when the other 3 lost their growth ability during passages 5-7. The only culture that could be maintained longer than passage 35 was designated as PSU-SK-1, a culture derived from an 8-year-old boy with bilateral WT and WAGR syndrome. The patient had a germline mutation of WT1, Arg413Stop, which caused WT1 protein truncation at exon 8 .

\section{Morphology and growth of PSU-SK-1}

Early passages of PSU-SK-1 showed polygonal cells with a large nucleus intermixed with spindle shaped cells resembling fibroblasts. As the culture progressed, the cell shapes became homogenously multipolar with varying length cell processes. The average cell size was large and most of the cells showed a prominent nucleolus. H\&E staining showed eosinophilic nuclear stains and faint hematoxylin stains of the cytoplasm (Figure 1). In the growth study, the cells usually reached their log phase of growth on the 16th hour of seeding and reached $80 \%$ confluence at the 70th hour. Average doubling time was 24 hours (Figure 2). The growth rate started to slow during passage 28-32 and the cells showed no further growth beyond passage 35 . In the cell cycle study, the G1/S fraction increased from $49.7 \%$ in passage 5 to $83.0 \%$ in passage 30 (Figure 3).

\section{Molecular studies and protein expression}

Mutation studies using tumor DNA from passage 20 showed homozygous mutation of WT1 (Arg413Stop) and concomitant heterozygous mutation of CTNNB1 (Ser45Pro). WTX and p53 mutation analysis showed negative results. Karyotyping showed a normal male karyotype. On immunocytochemistry, PSU-SK-1 showed intense 
nuclear staining of $\beta$-catenin (Figure 4). The cells were also marked with AE1/AE3 and showed weakly positive immunoreactivity for myogenin and myoD1.
On Western blot study of WT related proteins, PSU-SK-1 expressed WT1 and $\beta$-catenin and showed negative WTX expression (Figure 5).
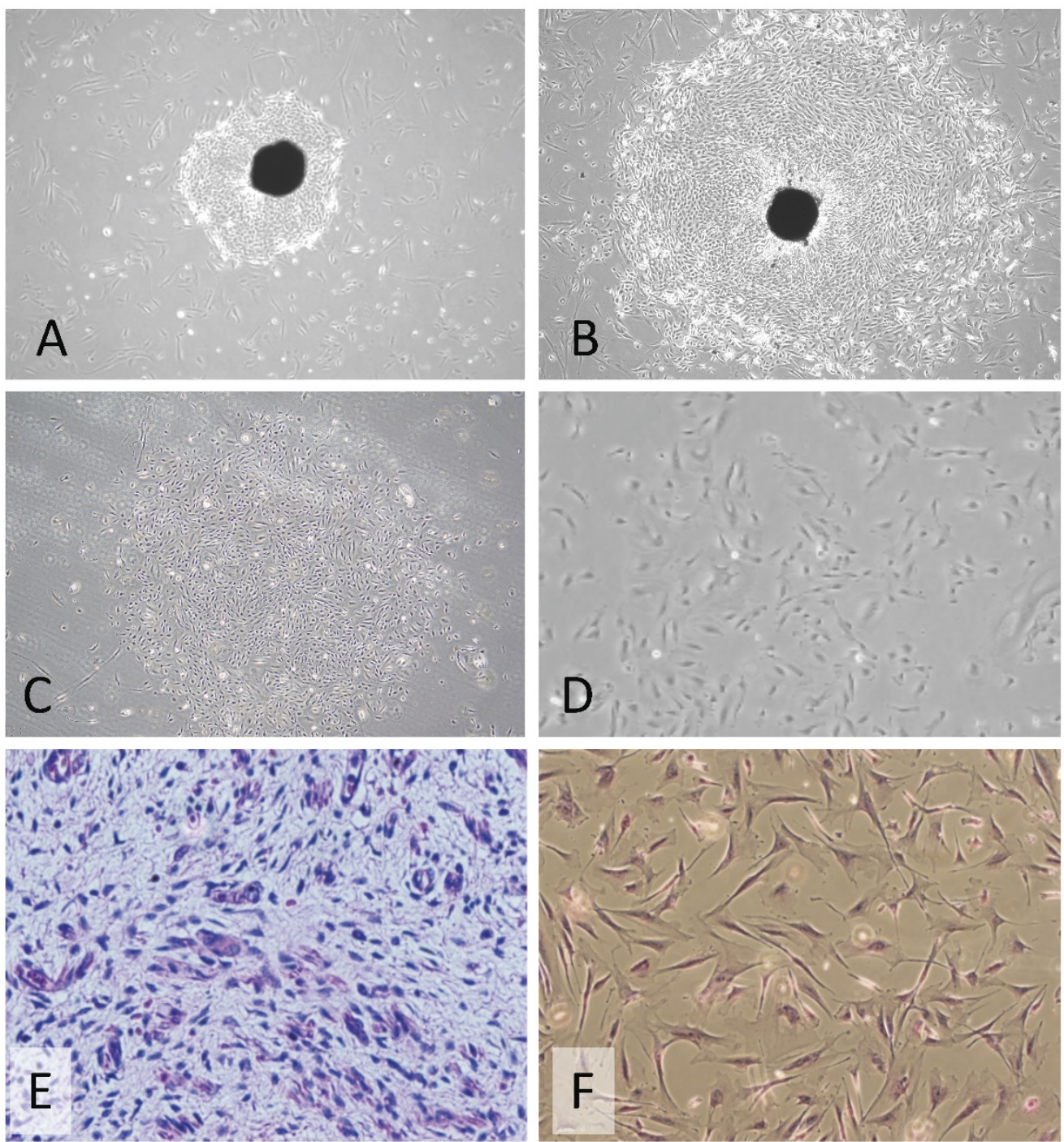

Figure 1. Morphology of a primary culture of PSU-SK-1. A-B) The early culture showed outgrowth cancer cells from the tumor tissue (20X magnification). C-D) After differential trypsinization and single clone selection. E) Histopathology of the original Wilms tumor tissue. F) Hematoxylin and Eosin stains of the cell culture at passage 10 , showing polygonal cells with bipolar cell processes, ovoid nuclei and a prominent nucleolus (40X magnification).
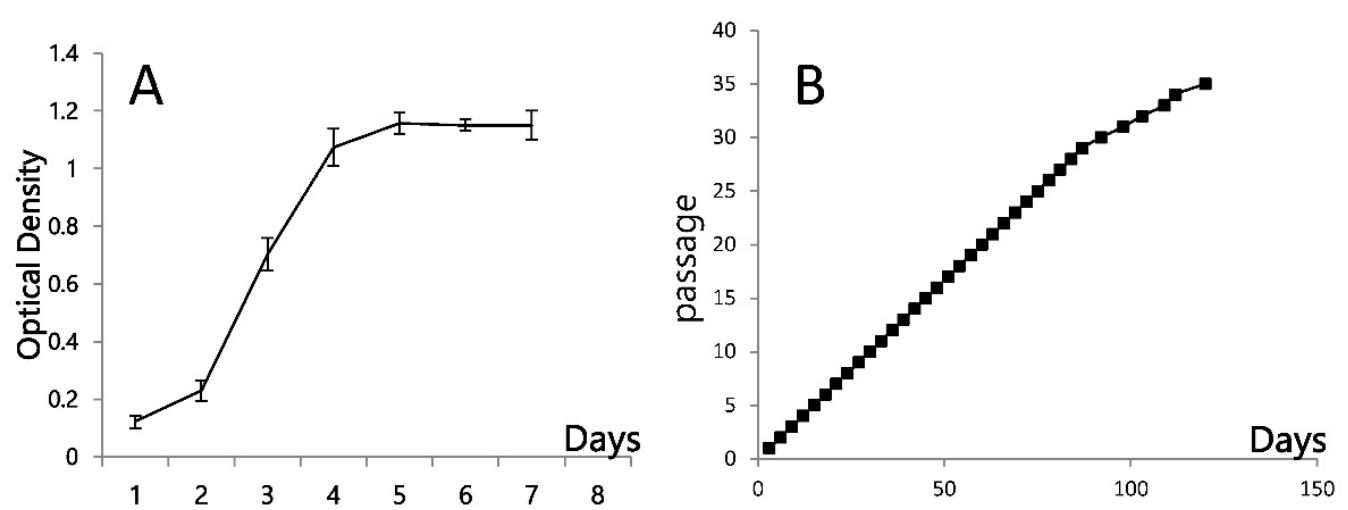

Figure 2. Growth dynamics of PSU-SK-1 A) Cellular growth as shown by MTT assay. B) Cell progression in continuous culture. 

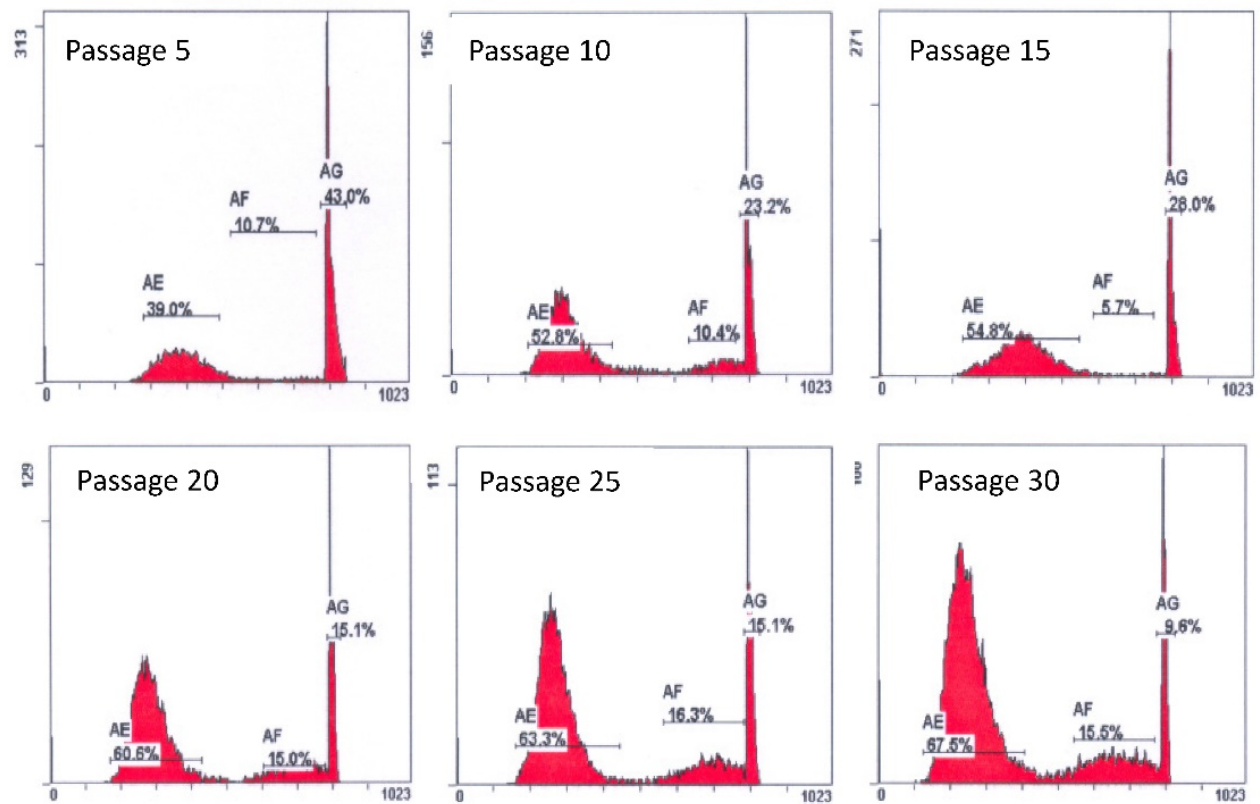

Figure 3. Cell cycle studies of various passages of PSU-SK-1. The G1-S fraction increased from $49.7 \%$ in passage 5 to $83.0 \%$ in passage 30 .

\section{Tissue}
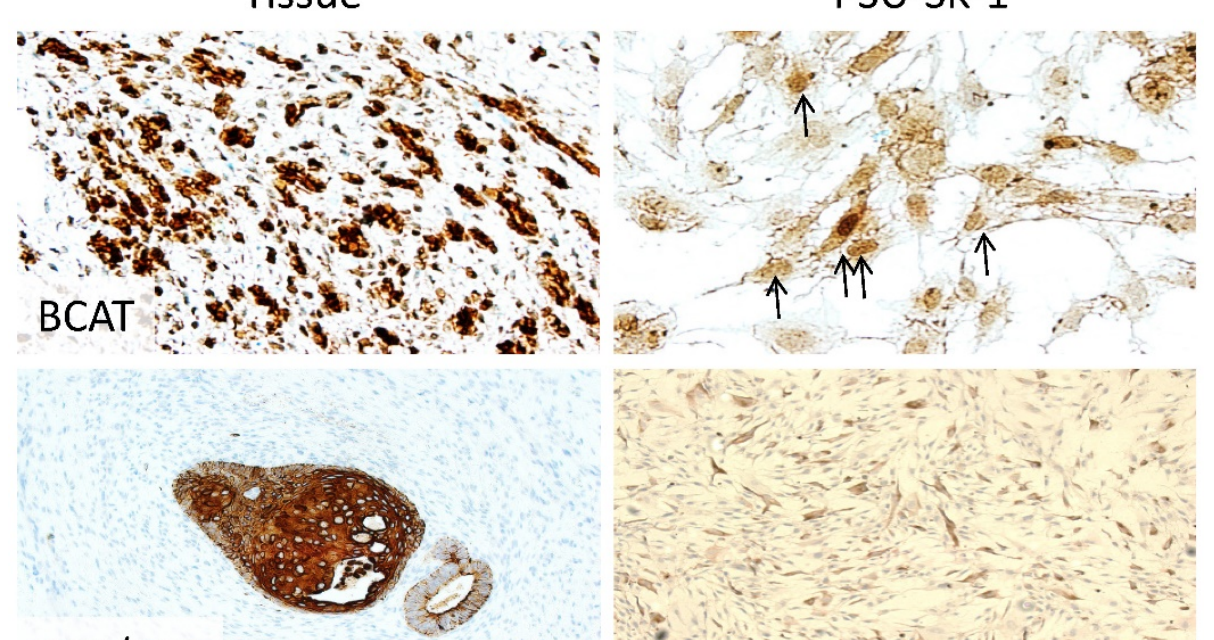

\section{AE1/AE3}
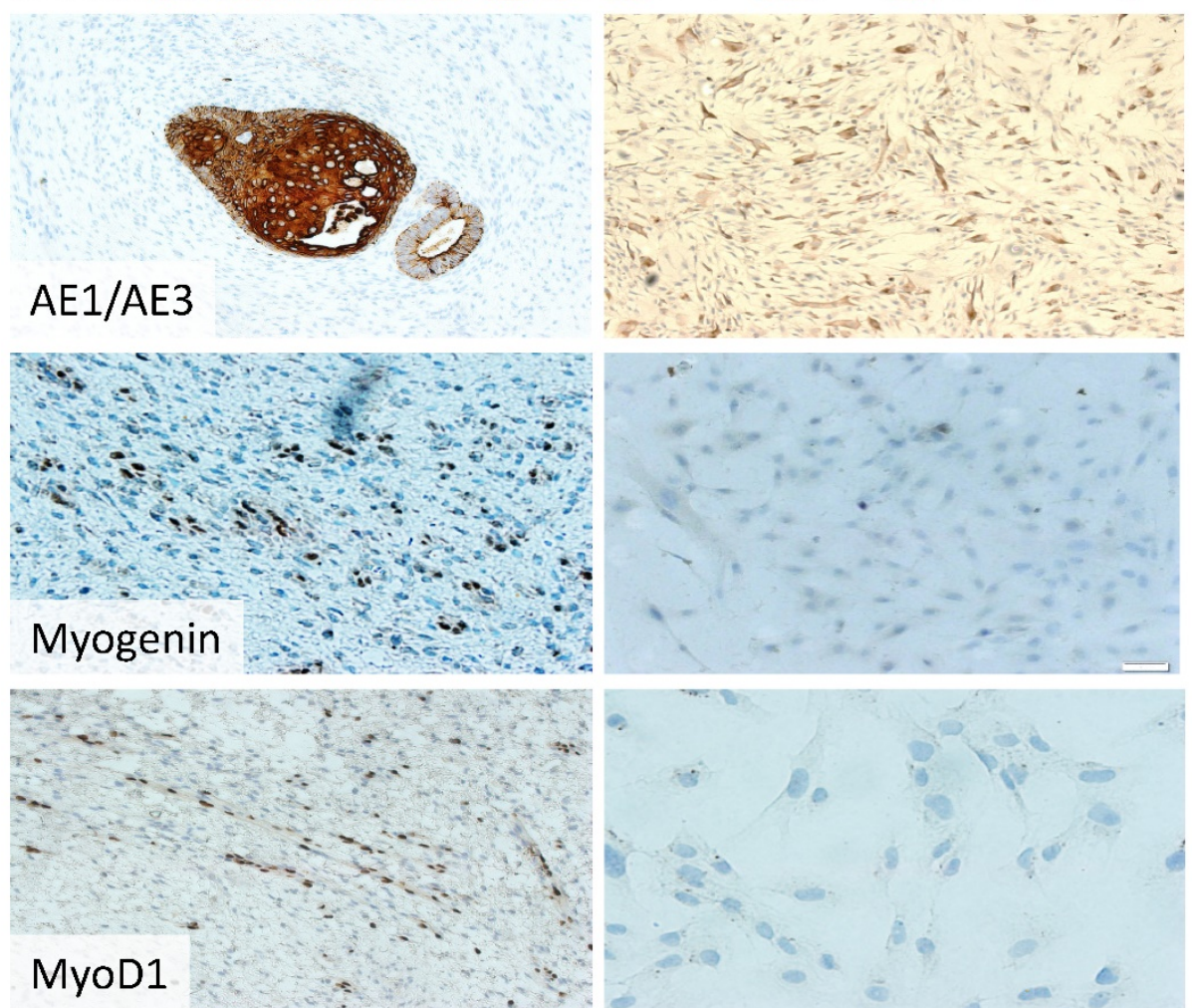

Figure 4. Immunohistochemistry of the original Wilms tumor and PSU-SK-1. The cells showed nuclear staining of $\beta$-catenin and cytokeratin (AE1/AE3). MyoD1 and myogenin gave weakly positive immunoreactivity. 


\section{Characteristics of cancer in PSU-SK-1}

On wound healing assay, PSU-SK-1 showed an ability to migrate and heal the wound within 24 hours. The cells had 55\% migration ability and had invasion ability at $27 \%$ of A549 (Figure 6). On gelatin zymography, PSU-SK-1 showed high expression of MMP (Figure 7). PSU-SK-1 failed to grow in soft agar. In addition, xenotransplantation showed no tumor growth.

\section{Senescence and senescence associated protein}

PSU-SK-1 in the later passages (> passage 30 ) grew significantly slower than the earlier passages.
Doubling time in passage 30 was 72 hours, compared to 24 hours in passage 7. Morphological observations found that the cells showed larger cell processes and cytoplasmic areas. On $\beta$-galactosidase staining, cells in the later passages showed a larger positive stain (Figure 8). Western blot studies showed increased expression of p21 and Cyclin D1 in the later passages of the cells (Figure 9). A study of WNT signalling-related protein showed expression of $\beta$-catenin and TCF, which was reduced with cellular progression.

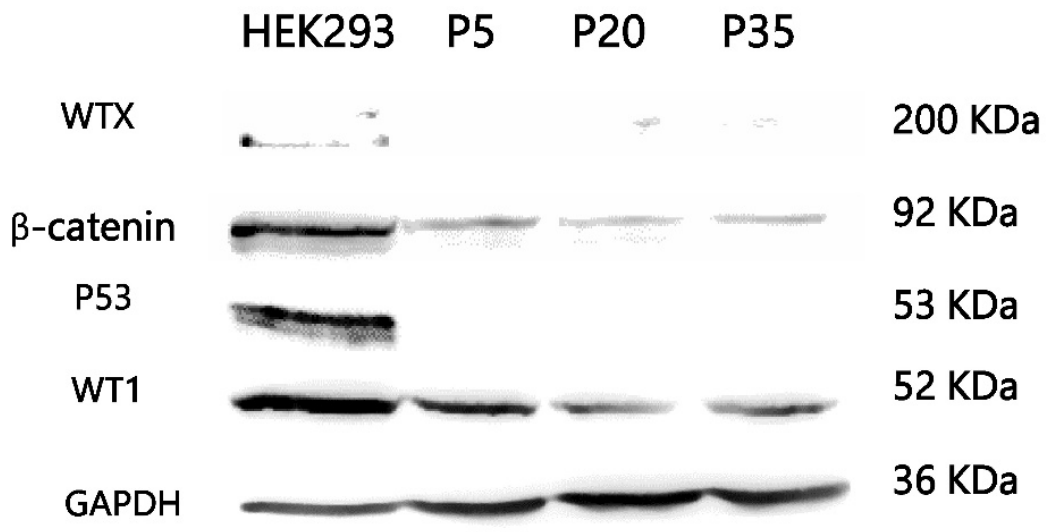

Figure 5. Western blotting of Wilms tumor related proteins. PSU-SK-1 expressed only $\beta$-catenin and WT1.

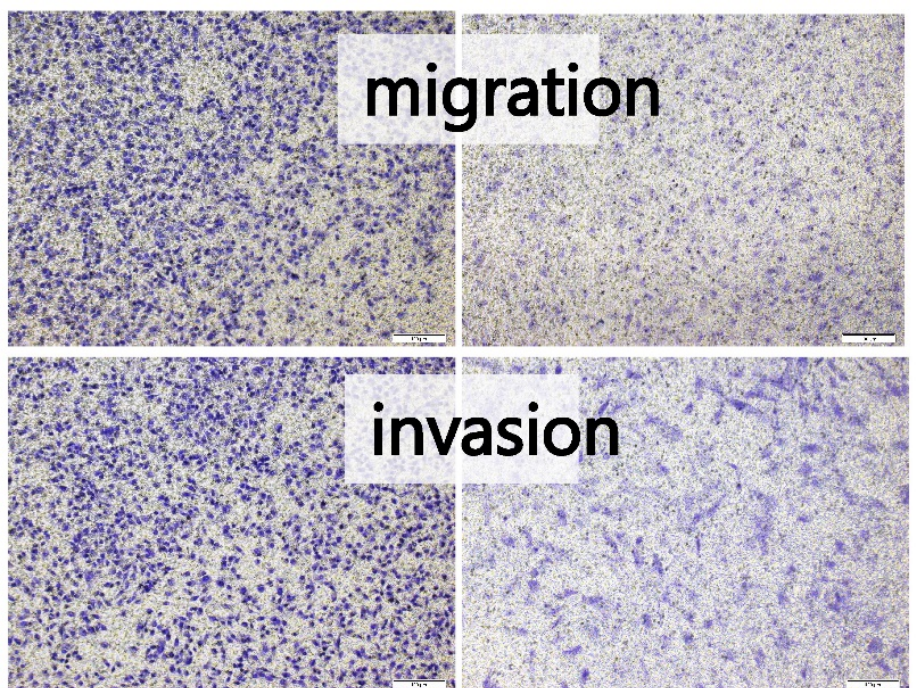

A549

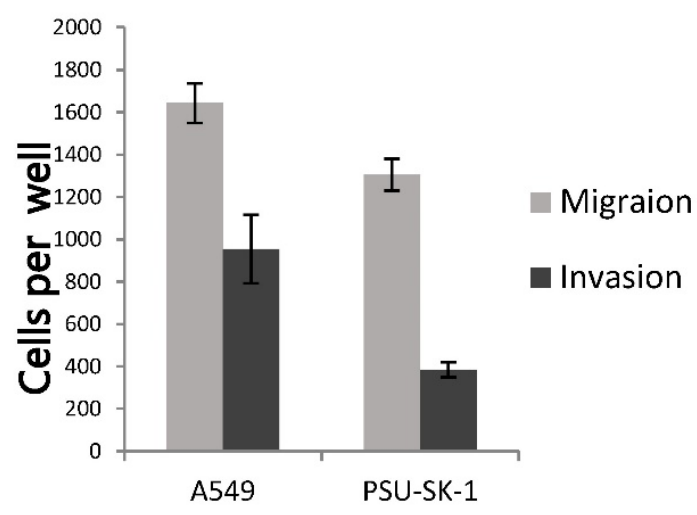

Figure 6. Migration and invasion assays of PSU-SK-1 by the Transwell method. The figures on the left show cells that could migrate or invade to the opposite side of the filters. The graph shows comparisons of the migrating and invading cells between PSU-SK-1 and a lung cancer cell line A569. 


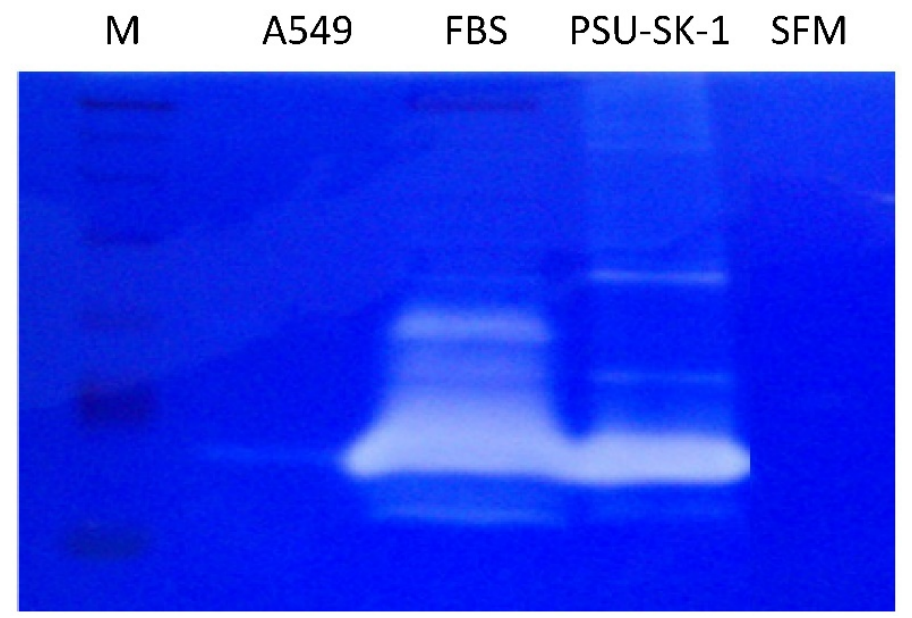

Figure 7. Gelatin zymography of PSU-SK-1 with A569 as a control. The Mr 72,000 band in PSU-SK-1 has previously been shown to correspond to MMP-2 activity. M: marker, FBS: Fetal Bovine Serum (The serum had intrinsic enzymatic activity and was used as a positive control), SFM: serum free media.
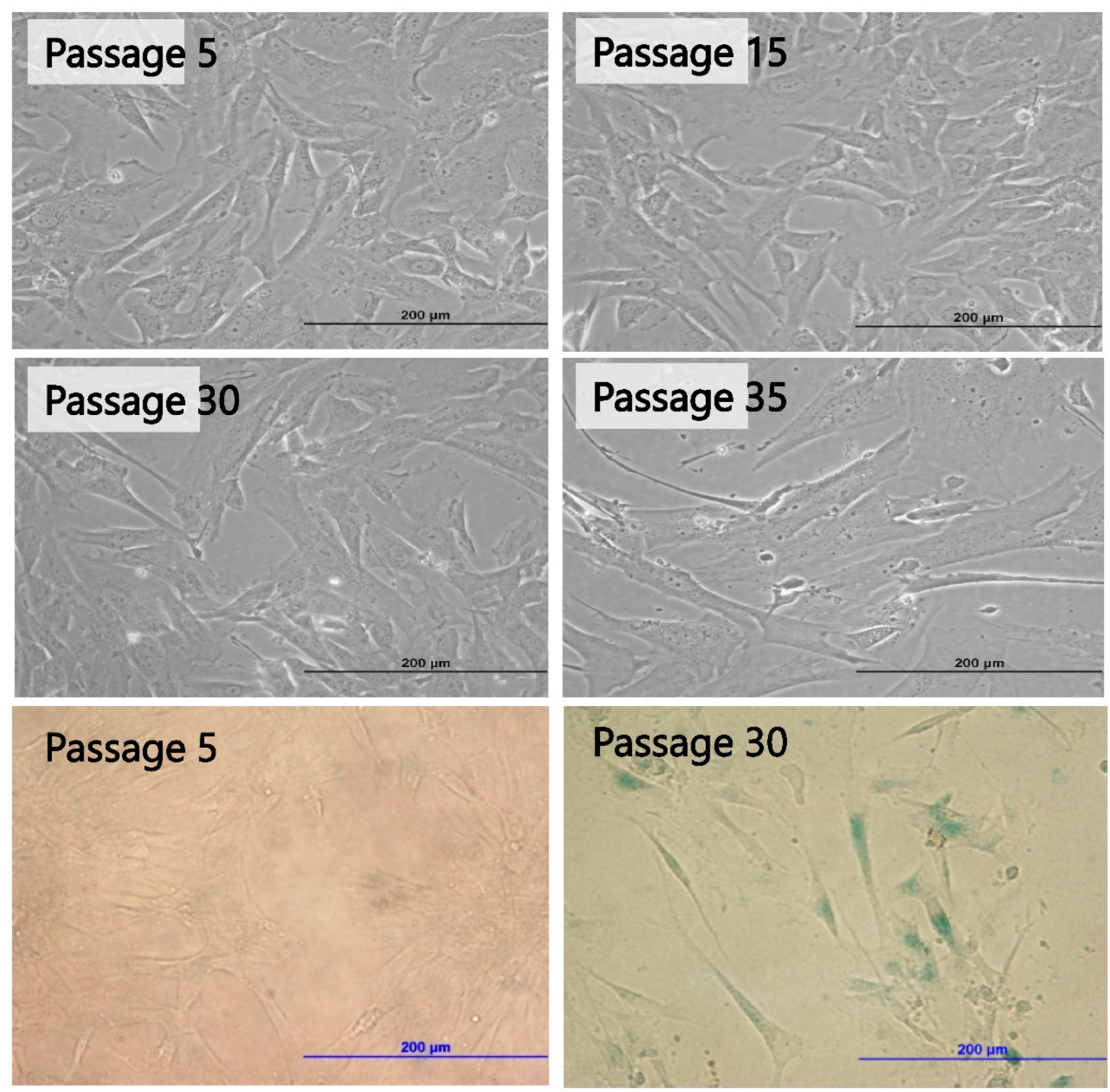

Figure 8. Morphological changes of PSU-SK- 1 in various passages (upper 4 Figures) and senescence-associated $\beta$-galactosidase (SA- $\beta$-Gal) stained for senescence cells (bottom 2 Figures), showing larger cell size and positive SA- $\beta-$-Gal in passage 30. 

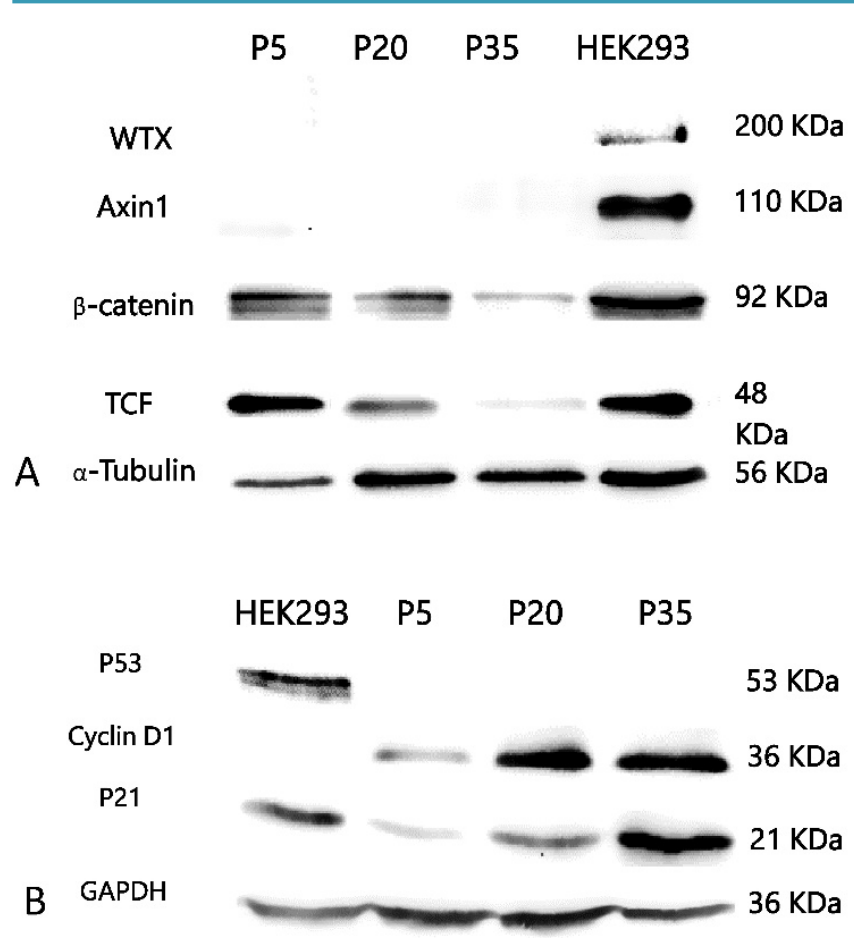

Figure 9. Western blotting study of Wnt signaling related proteins $A$ ) and cell-cycle control proteins B). Late passage cells (passage 30) showed decreased $\beta$-catenin and TCF expression, while expression of $\mathrm{p} 21$ and cyclin D1 were increased.

\section{Discussion}

In-vitro culture of WT is a major obstacle in understanding the pathogenesis of the disease [16]. WT is an embryonal tumor with a clinical characteristic of being highly invasive despite slow tumor growth. A majority of our patients were diagnosed at 3-5 years of age with around $45 \%$ already having metastasis at the time of diagnosis [19]. Most primary cultures from WT can be maintained no longer than 10-15 passages [20]. Cellular senescence is thought to be the main cause of growth cessation, although a recent study by Wegert and colleagues demonstrated progressive shortening of the telomere with in-vitro cultivation [16].

As with other embryonal tumors, tumorigenesis of WT is driven by the Wnt signaling pathway. Mutations of CTNNB1 and nuclear accumulation of $\beta$-catenin are hallmarks of Wnt activation [21]. Both features marked WT tumor cells in our study and confirmed that the cells in later passage were not fibroblasts. Previous studies from other groups have suggested that mesenchymal component of WT had a longer in-vitro lifespan when compared to the blastemal or epithelial lineages [15-17]. The morphology of PSU-SK-1 in the early passages resembles epithelial cells and expresses cytokeratin, implying that the early growth is predominated with blast/epithelial differentiation and later passage cells switch their polarity to the mesenchymal lineage. Migration and invasion capabilities suggest that PSU-SK-1 has cancer characteristics although the cells are not aggressive enough to grow independently in soft agar or in a xenotransplantation model.

Although PSU-SK-1 was successfully propagated longer than the usual WT cultures, the cells grow slower following passage 30 . This slower progression and mesenchymal differentiation of the PSU-SK-1 in its late passages was concomitant with positive SA- $\beta$ galactosidase staining, which marked the cellular senescence process [22]. The event of senescence was also concordant with reduction in $\beta$-catenin and its downstream protein, TCF, expression. As the mutations of CTNNB1 remained detectable in the later passages, mechanisms that reduce expression of the protein or provide alternative pathway of $\beta$-catenin degradation may exist. Wnt signaling inhibitors secreted by senescence-associated phenotypes of the tumor cells might be associated with the reduced expression of $\beta$-catenin. Consistent with the reduction of $\beta$-catenin protein, larger proportions of cells remained in the G1/S phase of the cell cycle.

A study of cell-cycle related proteins demonstrated that p21 increased with advanced cultivation. Expression of p21 in normal cells is governed by p53, a sensor of cellular stress or DNA damage. Previous studies have demonstrated that activation of p21 could also occur independently of p53 [23, 24]. In the colorectal cancer cell line HCT116, induction of p21 is activated by NFKB/p65 dependent system [24]. A recent study in an adrenal cancer cell line, H295R, showed that suppression of $\beta$-catenin expression up-regulated p21, p27 and p57 expression and inhibited cellular growth [25]. The study did not examine for alteration in p53 expression. As p53 did not show expression in PSU-SK-1, we speculate that p21 expression in the cells was not related to p53 protein. Reduction of Wnt signaling and/or increased expression of cyclin D1 might explain the increased expression of $\mathrm{p} 21$.

In conclusion, our study established a continuous culture of WT with molecular markers of CTNNB1 and WT1 mutations. The cells reached their proliferative limitation at the late passages which could be explained by p21 induced cellular senescence. Without p53, p21 can be induced by other signals including K-RAS which has been reported to function together with $\beta$-catenin in WT tumorigenesis in murine model $[26,27]$. Loss of normal WT1 might also result in induction of the senescence process in cells with active K-RAS [28]. In addition, decreased activation of the Wnt signalling might be responsible for the induction of the expression of p21. The main 
limitation of our study was that we cannot explain some molecular events such as increased Cyclin D1 expression in the later passages. Further studies with this established cell line are required.

\section{Acknowledgement}

This work was partially funded by a grant from The Office of the Higher Education Commission of Thailand. Korkiat Theerakitthanakul was supported by a CHE Ph.D. Scholarship. The authors thank Kanda Tongmitr for her assistance with the immunohistochemical techniques. Dave Patterson edited the manuscript.

\section{Competing Interests}

The authors have declared that no competing interest exists.

\section{References}

1. Davidoff AM. Wilms tumor. Adv Pediatr. 2012;59:247-67.

2. Dome JS, Graf N, Geller JI, Fernandez CV, Mullen EA, Spreafico F, et al. Advances in Wilms Tumor Treatment and Biology: Progress Through International Collaboration. J Clin Oncol. 2015;33:2999-3007.

3. Beckwith JB, Kiviat NB, Bonadio JF. Nephrogenic rests, nephroblastomatosis, and the pathogenesis of Wilms' tumor. Pediatr Pathol. 1990;10:1-36.

4. Deng C, Dai R, Li X, Liu F. Genetic variation frequencies in Wilms' tumor: A meta-analysis and systematic review. Cancer Sci. 2016;107:690-9.

5. Maiti S, Alam R, Amos CI, Huff V. Frequent association of beta-catenin and WT1 mutations in Wilms tumors. Cancer Res. 2000:60:6288-92.

6. Li CM, Kim CE, Margolin AA, Guo M, Zhu J, Mason JM, et al. CTNNB1 mutations and overexpression of Wnt/beta-catenin target genes in WT1-mutant Wilms' tumors. Am J Pathol. 2004;165:1943-53.

7. Lovvorn HN, 3rd, Pierce J, Libes J, Li B, Wei Q, Correa H, et al. Genetic and chromosomal alterations in Kenyan Wilms Tumor. Genes Chromosomes Cancer. 2015;54:702-15

8. Rivera MN, Kim WJ, Wells J, Driscoll DR, Brannigan BW, Han M, et al. An X chromosome gene, WTX, is commonly inactivated in Wilms tumor. Science. 2007;315:642-5.

9. Rivera MN, Haber DA. Wilms' tumour: connecting tumorigenesis and organ development in the kidney. Nat Rev Cancer. 2005;5:699-712.

10. Schedl A. Renal abnormalities and their developmental origin. Nat Rev Genet. 2007;8:791-802.

11. Sangkhathat S, Kanngurn S, Chaiyapan W, Gridist P, Maneechay W. Wilms' tumor 1 gene (WT1) is overexpressed and provides an oncogenic function in pediatric nephroblastomas harboring the wild-type WT1. Oncol Lett. 2010;1:615-9.

12. Garvin AJ, Re GG, Tarnowski BI, Hazen-Martin DJ, Sens DA. The G401 cell line, utilized for studies of chromosomal changes in Wilms' tumor, is derived from a rhabdoid tumor of the kidney. Am J Pathol. 1993:142:375-80.

13. Alami J, Williams BR, Yeger H. Derivation and characterization of a Wilms' tumour cell line, WiT 49. Int J Cancer. 2003;107:365-74.

14. Li MH, Yamase H, Ferrer F. Characterization of a WiT49 cell line derived orthotopic model of Wilms tumor. Pediatr Blood Cancer. 2010;54:316-8.

15. Royer-Pokora B, Busch M, Beier M, Duhme C, de Torres C, Mora J, et al. Wilms tumor cells with WT1 mutations have characteristic features of mesenchymal stem cells and express molecular markers of paraxial mesoderm. Hum Mol Genet. 2010;19:1651-68

16. Wegert J, Bausenwein S, Roth S, Graf N, Geissinger E, Gessler M. Characterization of primary Wilms tumor cultures as an in vitro model. Genes Chromosomes Cancer. 2012;51:92-104.

17. Faussillon M, Murakami I, Bichat M, Telvi L, Jeanpierre C, Nezelof C, et al. Molecular cytogenetic anomalies and phenotype alterations in a newly established cell line from Wilms tumor with diffuse anaplasia. Cancer Genet Cytogenet. 2008;184:22-30.

18. Smith MA, Morton CL, Phelps D, Girtman K, Neale G, Houghton PJ. SK-NEP-1 and Rh1 are Ewing family tumor lines. Pediatr Blood Cancer. 2008;50:703-6.

19. Sangkhathat S, Chotsampancharaen T, Kayasut K, Patrapinyokul S, Chiengkriwate $\mathrm{P}$, Kitichet $\mathrm{R}$, et al. Outcomes of pediatric nephroblastoma in southern Thailand. Asian Pac J Cancer Prev. 2008;9:643-7.

20. Garvin AJ, Sullivan JL, Bennett DD, Stanley WS, Inabnett T, Sens DA. The in vitro growth, heterotransplantation, and immunohistochemical characterization of the blastemal component of Wilms' tumor. Am J Pathol. 1987;129:353-63.
21. Koesters R, Ridder R, Kopp-Schneider A, Betts D, Adams V, Niggli F, et al. Mutational activation of the beta-catenin proto-oncogene is a common event in the development of Wilms' tumors. Cancer Res. 1999;59:3880-2.

22. Campisi J. Aging, cellular senescence, and cancer. Annu Rev Physiol. 2013;75:685-705

23. Aliouat-Denis CM, Dendouga N, Van den Wyngaert I, Goehlmann H, Steller $\mathrm{U}$, van de Weyer I, et al. p53-independent regulation of p21Waf1/Cip1 expression and senescence by Chk2. Mol Cancer Res. 2005;3:627-34.

24. Ma S, Tang J, Feng J, Xu Y, Yu X, Deng Q, et al. Induction of p21 by p65 in p53 null cells treated with Doxorubicin. Biochim Biophys Acta. 2008;1783:935-40.

25. Salomon A, Keramidas M, Maisin C, Thomas M. Loss of beta-catenin in adrenocortical cancer cells causes growth inhibition and reversal of epithelial-to-mesenchymal transition. Oncotarget. 2015;6:11421-33.

26. Clark PE, Polosukhina D, Love $\mathrm{H}$, Correa $\mathrm{H}$, Coffin $\mathrm{C}$, Perlman EJ, et al. beta-Catenin and K-RAS synergize to form primitive renal epithelial tumors with features of epithelial Wilms' tumors. Am J Pathol. 2011;179:3045-55.

27. Yi Y, Polosukhina D, Love HD, Hembd A, Pickup M, Moses HL, et al. A Murine Model of K-RAS and beta-Catenin Induced Renal Tumors Expresses High Levels of E2F1 and Resembles Human Wilms Tumor. J Urol. 2015;194:1762-70.

28. Vicent S, Chen R, Sayles LC, Lin C, Walker RG, Gillespie AK, et al. Wilms tumor 1 (WT1) regulates KRAS-driven oncogenesis and senescence in mouse and human models. J Clin Invest. 2010;120:3940-52. 